\title{
Impact of intraoperative magnetic resonance imaging on gross total resection, extent of resection, and residual tumor volume in pituitary surgery: systematic review and meta-analysis
}

\author{
Victor E. Staartjes ${ }^{1} \cdot$ Alex Togni-Pogliorini $^{1} \cdot$ Vittorio Stumpo $^{1} \cdot$ Carlo Serra $^{1}\left(\mathbb{D} \cdot\right.$ Luca Regli $^{1}$
}

Accepted: 15 April 2021 / Published online: 4 May 2021

(c) The Author(s) 2021

\begin{abstract}
Background Residual tumor tissue after pituitary adenoma surgery, is linked with additional morbidity and mortality. Intraoperative magnetic resonance imaging (ioMRI) could improve resection. We aim to assess the improvement in gross total resection (GTR), extent of resection (EOR), and residual tumor volume (RV) achieved using ioMRI.

Methods A systematic review was carried out on PubMed/MEDLINE to identify any studies reporting intra- and postoperative (1) GTR, (2) EOR, or (3) RV in patients who underwent resection of pituitary adenomas with ioMRI. Random effects meta-analysis of the rate of improvement after ioMRI for these three surgical outcomes was intended.

Results Among 34 included studies (2130 patients), the proportion of patients with conversion to GTR $(\Delta \mathrm{GTR})$ after ioMRI was $0.19(95 \% \mathrm{CI} 0.15-0.23)$. Mean $\Delta \mathrm{EOR}$ was $+9.07 \%$ after ioMRI. Mean $\Delta \mathrm{RV}$ was $0.784 \mathrm{~cm}^{3}$. For endoscopically treated patients, $\Delta$ GTR was 0.17 (95\% CI 0.09-0.25), while microscopic $\Delta$ GTR was 0.19 (95\% CI 0.15-0.23). Low-field ioMRI studies demonstrated a $\Delta$ GTR of 0.19 (95\% CI 0.11-0.28), while high-field and ultra-high-field ioMRI demonstrated a $\Delta$ GTR of 0.19 (95\% CI $0.15-0.24$ ) and 0.20 (95\% CI 0.13-0.28), respectively.

Conclusions Our meta-analysis demonstrates that around one fifth of patients undergoing pituitary adenoma resection convert from non-GTR to GTR after the use of ioMRI. EOR and RV can also be improved to a certain extent using ioMRI. Endoscopic versus microscopic technique or field strength does not appear to alter the impact of ioMRI. Statistical heterogeneity was high, indicating that the improvement in surgical results due to ioMRI varies considerably by center.
\end{abstract}

Keywords Pituitary $\cdot$ Adenoma $\cdot$ Intraoperative magnetic resonance imaging $\cdot$ Imaging $\cdot$ Extent of resection $\cdot$ Gross total resection

\section{Introduction}

Pituitary adenomas (PA) are among the most common intracranial neoplasms, an can become symptomatic due to endocrine and mass effect manifestations [1]. Transsphenoidal surgery (TSS), either endoscopic or microsurgical, represents the standard of care for those patients requiring

Victor E. Staartjes and Alex Togni-Pogliorini have contributed equally to this work and share first authorship.

Carlo Serra

c.serra@hotmail.it

1 Machine Intelligence in Clinical Neuroscience (MICN) Laboratory, Department of Neurosurgery, Clinical Neuroscience Center, University Hospital Zurich, University of Zurich, Frauenklinikstrasse 10, 8091 Zurich, Switzerland treatment, except for prolactinomas which can often be managed medically [2-5]. In most patients, gross total resection (GTR) is the surgical goal and can be achieved in the majority of patients $[2,6]$. The likelihood of GTR is determined by several factors, including - but not limited to-PA diameter and volume, sellar and dural anatomy, histological features, cavernous sinus invasion, as well as surgical strategy [2, 7-10]. Classifications have been developed for pre-operative evaluation of resectability, such as the Knosp classification and the Zurich pituitary score [7, 9, 11, 12].

In order to increase the proportion of patients where an optimal surgical resection is achieved, a number of studies evaluated the implementation of intra-operative MRI (ioMRI) which, in principle, allows to more accurately identify tumor remnants and has been extensively reported to improve surgical result, independently of surgical strategy [11, 13-19]. This in turn reduces the need for revision 
surgery, which has a higher inherent risk compared to primary interventions [20,21]. Although several authors have reported their experience with low-field, high-field, and ultra-high field ioMRI, there is currently a lack of sufficiently powered studies to assess the real benefits in terms of surgical outcomes (GTR, extent of resection [EOR], and residual tumor volume [RV]). [15, 16, 18, 22, 23] Moreover, controversies exist in the literature on the impact of ioMRI in TSS, whether endoscopic or microsurgical [15, 17, 22]. Concerns over false positive and false negative findings, as well as excessive costs—and resulting limited availabilityand increased surgical time have been raised, and warrant additional scrutiny [24].

Systematic reviews and statistical meta-analyses can lead to more realistic results through incorporation of data from many centers and consequently many surgeons, as well as increasing statistical power compared to single studies. We systematically reviewed the literature to evaluate the impact of low-, high- and ultra-high field ioMRI on GTR, EOR, and $\mathrm{RV}$ in endoscopic or microscopic transsphenoidal pituitary adenoma surgery.

\section{Materials and methods}

\section{Overview}

A systematic review was carried out to identify any studies reporting intra- and postoperative (1) GTR (rate of radiological gross total resection), (2) EOR (proportion of resected tumor volume compared to the preoperative tumor volume), or (3) RV (residual tumor volume in $\mathrm{cm}^{3}$ ) in patients who underwent resection of pituitary adenomas with ioMRI guidance. Title and abstract screening, full-text review, and data extraction were handled independently by two reviewers (VES and ATP), and disagreements at any stage were resolved by discussion and consensus. Persisting disagreements were resolved by discussion with a third reviewer (CS). We followed the preferred reporting items for systematic reviews and meta-analyses (PRISMA) protocol [25]. This review was registered on PROSPERO (www.crd.york. ac.uk/prospero, Record ID: 177126).

\section{Search strategy}

The PubMed / MEDLINE database was searched to identify eligible articles. The search strategy included combinations of the following terms: pituitary; intraoperative MRI; magnetic resonance imaging; intraoperative; intraoperative imaging; MRI; gross total resection; GTR; extent of resection; EOR; residual; and residual volume (see Table, Supplementary material 1). Word variations and exploded medical subject headings were searched for whenever feasible.
Additionally, reference lists were hand-searched to identify further studies of interest. The last comprehensive search was conducted on March 16th 2020.

\section{Study selection}

Only in vivo studies enrolling humans of all age groups in English, Italian, French, Dutch, and German were considered. As a small number of controlled trials were anticipated, prospective and retrospective single-arm cohort studies and case series of adult and pediatric individuals were also included. Case reports and small case series with less than 5 patients were excluded. To be considered, patients had to undergo endoscopic or microscopic trans-sphenoidal resection of pituitary adenomas using ioMRI. Studies had to assess at least one of the three abovementioned outcomes of interest at a minimum of the intraoperative and postoperative time points. In this way, we were able to rate the potential improvement in resection achieved after intraoperative imaging. Studies reporting only resection of Rathke cleft cysts, craniopharyngiomas, or other lesions were excluded. We also excluded studies dealing mainly with transcranial or combined procedures. Studies dealing primarily with patients in which decompression only was the surgical target were excluded. Studies reporting the outcomes of interest with a mix of targeted GTR and STR (i.e. a realistic caseload) were included. Exact cohort duplicates were excluded, although we did include updates of previously published cohorts with a sample size increase of at least $50 \%$.

\section{Data extraction and quality assessment}

We extracted the following information if available from all included publications: study design and year of publication, number of patients, mean patient age and gender distribution, endoscopic or microscopic surgery, low-field $(<1.5 \mathrm{~T})$, high-field ( $\geq 1.5 \mathrm{~T})$, or "ultra-high" field ( $\geq 3 \mathrm{~T})$ ioMRI [26], as well as intra- and postoperatively at least one of (1) GTR, (2) EOR, (3) RV. We also assessed whether studies evaluated primarily primary adenoma resections, or primarily revision surgeries. If exclusively reported separately, we included the outcome measures for those patients with targeted GTR. Methodological quality of included studies was graded using the newcastle-ottawa quality assessment scale for cohort studies [27].

\section{Statistical meta-analysis}

The methodology for statistical meta-analysis of related samples is controversial and not well-established. As we were interested in the effect size of ioMRI on GTR, EOR, and RV before vs. after ioMRI, we calculated the individual differences (before vs. after ioMRI) in these three outcomes 
per study. These effect sizes were then meta-analyzed, if enough appropriate data was available. Because major heterogeneity among the studies in terms of demographics, surgical techniques, and so forth was expected, a random effects meta-analysis was decided upon. $\triangle$ GTR was meta-analyzed using the generic inverse variance method, with a FreemanTukey Double arcsine transformation to estimate overall proportions [28]. A formal meta-analysis of $\triangle E O R$ and $\Delta R V$ was not possible as most studies reporting these data did not provide measures of variance (i.e. standard deviations). For this reason, we were only able to calculate patient-weighted means for $\triangle E O R$ and $\triangle R V$ [29]. We performed stratified analyses for endoscopic and microscopic surgery, as well as for low versus high field ioMRI. Additionally, we evaluated the effect of ioMRI in the "ultra-high" field cohorts $(\geq 3 \mathrm{~T})$ [26]. All statistical analyses were carried out in R using the "meta" package [30]. Forest plots were generated to illustrate the main results of the meta-analysis.

\section{Results}

\section{Literature search}

The PubMed/MEDLINE search yielded 432 articles to which an additional 5 were added after retrieval from other sources. A PRISMA flowchart is shown in Supplementary Fig. 1. After duplicate removal $(n=1), 436$ records were screened, and 58 were assessed for eligibility through fulltext screening. Of the 34 publications included for qualitative synthesis, all were also eligible for quantitative metaanalysis.[11, 13, 16-20, 22-24, 31-55]

\section{Included study characteristics}

Overview of the characteristics of the included studies is reported in Table 1. We identified 12 studies reporting use of low-field ioMRI. Sixteen studies used high-field ioMRI, six studies used ultra-high field ioMRI. With respect to surgical technique, 14 studies used an endoscopic resection technique while 19 studies used the microscopic technique. All included studies evaluated intra-operative and post-operative GTR rates, allowing the calculation of $\triangle$ GTR after ioMRI. Only 2 studies reported EOR improvement granted by use of ioMRI $[11,17]$, and only 4 assessed RV change after ioMRI [11, 17, 39, 44]. (Table 2).

\section{Gross total resection}

Random-effect meta-analysis showed that, in the 34 included studies (2130 patients), the proportion of patients with conversion to GTR $(\triangle \mathrm{GTR})$ after ioMRI was $0.19(95 \% \mathrm{CI}$
0.15-0.23). Heterogeneity — as measured by $\mathrm{I}^{2}$ statistic — was high with $78 \%$ ( $\mathrm{p}<0.01)$. (Fig. 1).

Extent of resection and residual tumor volume.

Formal meta-analysis was not possible for EOR and $\mathrm{RV}$, thus patient-weighted means were calculated instead (Table 3). Among 191 patients, $\triangle \mathrm{EOR}$ was $+9.07 \%$ after ioMRI on average.

Concerning RV, overall $\Delta R V$ was $0.784 \mathrm{~cm}^{3}$. Subgroup analysis stratified by surgical techniques was possible, with endo- $(n=73)$ and microscopic patients $(n=134)$ demonstrating an average $\Delta \mathrm{RV}$ of $0.503 \mathrm{~cm}^{3}$ and $1.183 \mathrm{~cm}^{3}$, respectively.

\section{ioMRI in endoscopic versus microscopic technique}

When only studies assessing endoscopic surgery $(n=14)$ were evaluated (1035 patients), $\triangle$ GTR proportion was 0.17 (95\% CI 0.09-0.25), while in studies performing microscopic TSS ( $\mathrm{n}=19,1048$ patients), the GTR proportion was 0.19 (95\% CI 0.15-0.23) (Fig. 2).

\section{Low- versus high- versus ultra high-field ioMRI}

Low-field ioMRI studies $(n=12)$ accounting for 691 patients demonstrated a $\triangle$ GTR proportion of $0.19(95 \%$ CI 0.11-0.28), while meta-analysis (Fig. 3) of publications reporting high-field ioMRI $(\mathrm{n}=16)$ among 1439 patients had a $\Delta$ GTR proportion of 0.19 (95\% CI 0.15-0.24). When studies employing ultra high-field ioMRI (Fig. 4) were metaanalyzed, $(n=6)$ the $\Delta$ GTR proportion was $0.20(95 \% \mathrm{CI}$ $0.13-0.28$ ) among 337 patients.

\section{Discussion}

Our meta-analysis demonstrated that the use of ioMRIon average — grants an additional conversion to GTR in PA patients undergoing surgery ranging between 15 and $23 \%$. EOR increased by an average of $9 \%$, and RV decreased by $0.784 \mathrm{~cm}^{3}$. In addition, when evaluating studies assessing ioMRI benefit in endoscopic TSS versus microscopic surgery separately, $\Delta$ GTR was similar. When comparing different magnetic field strengths, no major statistically significant differences could be accounted for.

Regarding the benefit of ioMRI in either microscopic or endoscopic surgery, a recent study by Soneru et al. compared literature data on GTR after pituitary adenoma resection, and found endoscopic TSS with or with- out ioMRI resulted in a similar rate of GTR when compared to patients undergoing ioMRI-assisted microscopic TSS for all pituitary adenomas [15]. For macroadenomas, the pooled rate of GTR in endoscopic TSS + ioMRI was higher than microscopic TSS + ioMRI. More importantly, Soneru et al. found that 
Table 1 Overview of the characteristics of the 34 included studies

\begin{tabular}{|c|c|c|c|c|c|c|c|c|}
\hline Author & Year & No. pts & $\begin{array}{l}\text { Microscopic/ } \\
\text { Endoscopic, } \mathrm{n}\end{array}$ & Field strength & NFPA, n (\%) & $\begin{array}{l}\text { Age, mean } \\
( \pm \text { SD or } \\
\text { range })\end{array}$ & Male, n (\%) & $\begin{array}{l}\text { Newcastle- } \\
\text { Ottawa scale } \\
(\mathrm{S} / \mathrm{C} / \mathrm{O})\end{array}$ \\
\hline \multicolumn{9}{|l|}{ Low-field } \\
\hline Ahn et al & 2008 & 51 & $51 / 0$ & 0.15 T Polestar N20 & NA & NA & NA & $3 / 0 / 3$ \\
\hline Berkmann et al & 2012 & 115 & $115 / 0$ & 0.15 T Polestar N20 & $79(69)$ & NA & NA & $3 / 0 / 3$ \\
\hline Bohinski et al & 2001 & 29 & $29 / 0$ & 0.3 T AIRIS II & $22(76)$ & $51(24-74)$ & $18(62)$ & $3 / 0 / 3$ \\
\hline Garcia et al & 2017 & 30 & $0 / 30$ & 0.15 T Polestar N30 & $15(50)$ & 55 & $13(43)$ & $3 / 0 / 3$ \\
\hline Hlavica et al & 2013 & 104 & $104 / 0$ & 0.15 T Polestar N20 & $104(100)$ & $59(22-86)$ & $57(55)$ & $3 / 0 / 3$ \\
\hline Jimenez et al & 2016 & 18 & $0 / 18$ & 0.15 T Polestar N20 & $10(56)$ & NA & NA & $3 / 0 / 3$ \\
\hline Martin et al & 1999 & 5 & $5 / 0$ & $0.5 \mathrm{~T}$ & $0(0)$ & $36.2(28-42)$ & $2(40)$ & $3 / 0 / 3$ \\
\hline Ramm-Pettersen et al & 2011 & 20 & $20 / 0$ & 0.5 T Signa SP & $16(80)$ & $54(23-71)$ & $13(65)$ & $3 / 0 / 3$ \\
\hline Schwartz et al & 2006 & 15 & $0 / 15$ & 0.12 T Polestar N10 & $11(73)$ & $49(29-67)$ & $9(60)$ & $3 / 0 / 3$ \\
\hline Steinmeier et al & 1998 & 18 & $18 / 0$ & $0.2 \mathrm{~T}$ & $15(83)$ & $21-79$ & $9(50)$ & $3 / 0 / 3$ \\
\hline Strange et al & 2019 & 231 & $0 / 231$ & 0.15 T Polestar N20 & $160(69)$ & $55.5(18-88)$ & $127(55)$ & $3 / 0 / 3$ \\
\hline Wu et al & 2009 & 55 & $55 / 0$ & 0.15 T Polestar N20 & $29(53)$ & $45.9( \pm 12.6)$ & $36(65)$ & $3 / 0 / 3$ \\
\hline \multicolumn{9}{|l|}{ High-field } \\
\hline Berkmann et al & 2014 & 85 & $85 / 0$ & 1.5 T Magnetom & $85(100)$ & $55( \pm 14)$ & $57(67)$ & $3 / 0 / 3$ \\
\hline Chen et al & 2012 & 13 & $13 / 0$ & 1.5 T Magnetom & NA & NA & NA & $3 / 0 / 3$ \\
\hline Dort et al & 2001 & 15 & $15 / 0$ & $1.5 \mathrm{~T}$ & NA & $50(15-80)$ & $8(53)$ & $3 / 0 / 3$ \\
\hline Gohla et al & 2019 & 42 & $42 / 0$ & 1.5 T Espree & $35(83)$ & $52(17-79)$ & $23(55)$ & $3 / 0 / 3$ \\
\hline Hlavac et al & 2019 & 111 & $66 / 45$ & 1.5 T Espree & $91(82)$ & $57.3(22-78)$ & $75(68)$ & $3 / 0 / 3$ \\
\hline Kuge et al & 2013 & 35 & $0 / 35$ & $1.5 \mathrm{~T}$ & $27(77)$ & $54.3( \pm 15.5)$ & $18(51)$ & $3 / 0 / 3$ \\
\hline Li et al & 2015 & 30 & $30 / 0$ & $1.5 \mathrm{~T}$ Espree & $9(30)$ & $36(21-65)$ & $13(43)$ & $3 / 0 / 3$ \\
\hline Nimsky et al & 2004 & 48 & $48 / 0$ & $1.5 \mathrm{~T}$ & NA & $\mathrm{NA}$ & NA & $3 / 0 / 3$ \\
\hline Nimsky et al & 2006 & 85 & $85 / 0$ & 1.5 T Magnetom & 85 (100) & NA & NA & $3 / 0 / 3$ \\
\hline Pal'a et al & 2017 & 96 & $68 / 28$ & $1.5 \mathrm{~T}$ Espree & $64(67)$ & $54(7-78)$ & $71(74)$ & $3 / 0 / 3$ \\
\hline Paterno et al & 2014 & 49 & $0 / 49$ & 1.5 T Espree & 49 (100) & NA & NA & \\
\hline Sylvester et al & 2015 & 156 & $115 / 41$ & 1.5 T Espree & NA & NA & NA & $3 / 0 / 3$ \\
\hline Szerlip et al & 2011 & 53 & $53 / 0$ & $1.5 \mathrm{~T}$ Espree & $39(74)$ & 49 (1.8 SEM) & $25(47)$ & $3 / 0 / 3$ \\
\hline Tanei et al & 2013 & 14 & $0 / 14$ & 1.5 T Magnetom & $0(0)$ & $37.4( \pm 11.8)$ & $2(14)$ & $3 / 0 / 3$ \\
\hline Zhang et al & 2017 & 137 & $0 / 137$ & 1.5 T Espree & $103(75)$ & $7-82$ & $73(53)$ & \\
\hline Zhang et al & 2019 & 133 & $0 / 133$ & 1.5 T Espree & $133(100)$ & $50( \pm 12)$ & $61(46)$ & $3 / 0 / 3$ \\
\hline \multicolumn{9}{|l|}{ Ultra-high-field } \\
\hline Fomekong et al & 2014 & 73 & $73 / 0$ & $3 \mathrm{~T}$ Intera & NA & $50(17-84)$ & $46(63)$ & $3 / 0 / 3$ \\
\hline Netuka et al & 2011 & 49 & NA & $3 \mathrm{~T}$ & NA & NA & NA & $3 / 0 / 3$ \\
\hline Qiu et al & 2012 & 49 & NA & 3 T Mangetom & NA & NA & NA & $3 / 0 / 3$ \\
\hline Serra et al & 2016 & 51 & $0 / 51$ & 3 T Mangetom & $33(65)$ & $52(21-83)$ & $27(53)$ & $3 / 0 / 3$ \\
\hline Staartjes et al & 2019 & 95 & $0 / 95$ & 3 T Magnetom & $65(68)$ & $53.8(20-82)$ & $53(56)$ & $3 / 0 / 3$ \\
\hline Zaidi et al & 2016 & 20 & $0 / 20$ & 3 T Verio & $14(70)$ & $51.6(34-72)$ & $9(45)$ & $3 / 0 / 3$ \\
\hline
\end{tabular}

NFPA non-functioning pituitary adenoma, $S D$ standard deviation, $N A$ not applicable

ioMRI lead to a higher rate of GTR than endoscopic TSS alone, even if comparisons were indirect $[15,55]$. Their results, however have to be interpreted cautiously due to great heterogeneity among the included studies, which could not be corrected by meta-regression $[2,15]$. It is important to consider that the contributions of ioMRI to GTR conversion are thought to derive mainly from identification of additional intrasellar remnants which are prone to safe surgical resection [13]. Additional advantages which may result from
ioMRI may include increased EOR and therefore decreased $\mathrm{RV}$ and early identification of complications [16, 52, 53]. There is even some weak evidence that early post-operative imaging correlates more poorly with long-term surgical outcome than intra-operative imaging [16].

Thus, focusing on GTR only may underestimate the resection improvement granted by ioMRI. A limited number of studies assessed EOR and RV improvement due to ioMRI. Therefore, we were unable to carry out statistical 


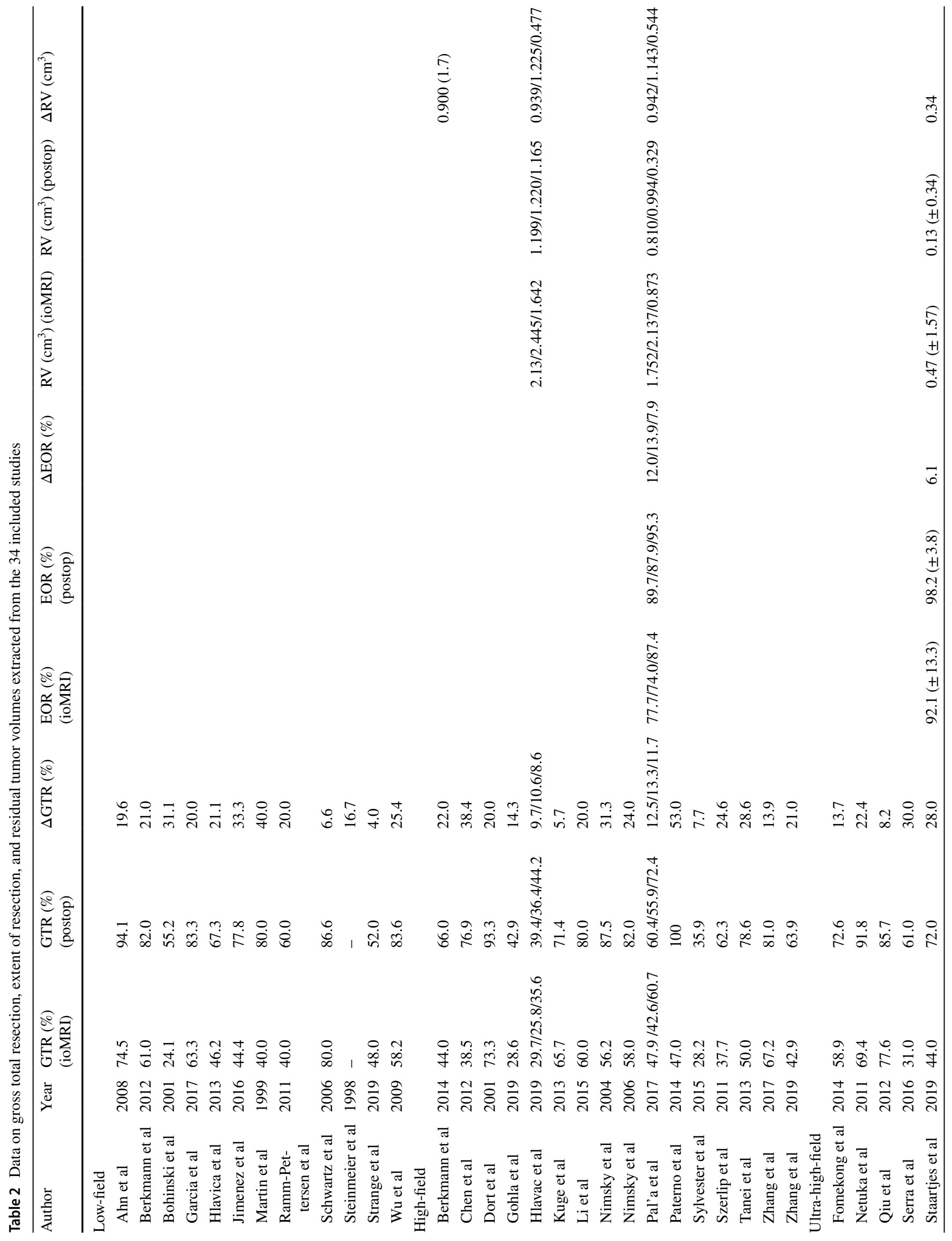


meta-analysis, although our numbers still show a small improvement in EOR and RV. Given the low number of studies and limited sample size, future studies should evaluate this question with appropriate design and methodology, including precise volumetric tumor remnant segmentation $[13,17]$. The improvement granted by increased extent of resection has been shown to positively influence progression free survival (PFS), and may also make the tumor remnant more amenable to salvage treatments such as radiosurgery or, more importantly, to spare the patient from revision surgery, which is intrinsically associated with increased risks $[37,49]$. Some authors also suggest that tumor remnants visualized using ioMRI in a significant number of patients may not be amenable to further safe resection, and that when aggressive resection is pursued, this may in turn lead to increased complications such as cerebrospinal fluid leak, arterial injury and hypopituitarism-even if the literature seem to rule out such occurrences [56].

In our study, we were unable to identify any selective advantage of high- or even ultra high-field compared to low-field ioMRI. This conclusion must be taken cautiously since we could not ascertain if the different patients cohorts were comparable concerning baseline variables known to affect the likelihood of achieving GTR. Published case series suggested that low-field ioMRI already improved GTR [18, 19, 37, 55, 57]. Potential explanations for this finding are that low-field MRI already provides visualization accurate enough to identify remnants amenable to further resection, but that those remnants that cannot be resected after either high- or low-field ioMRI are not amenable to resection, either way. For example, tumor remnants lateral to the carotids or invading the cavernous sinus profoundly may not be resettable even if detected at ioMRI.-There is however not enough data to assess if high- or ultrahigh field may provide better EOR and RV rates, being both outcomes particularly valuable in secreting adenomas. The evidence on this topic is controversial, as some authors report absence of false positive but variable false negative findings with low-field, but not with high-field ioMRI [18, 23]. The perceived improvement may be more relevant in patients with functioning PAs, where size of the residual volume is more closely linked with endocrine remission. It has been claimed that high-field ioMRI can possibly grant increased sensitivity in patients of subtotal resection specifically in microadenomas [37, 58]. At the same time, parasellar anatomy, cavernous sinus invasion and small lesions cannot be as reliably evaluated-according to some authors-with low-field than with high-field ioMRI [19].

The cost-benefit ratio favors ioMRI use, even when increased costs are accounted for as the increased rate of GTR reduces reoperations or additional therapies and their associated expenses, according to a recent analysis [55]. Limiting the use of such technology to patients where the 


\section{Study}

Ahn et al. 2008

Berkmann et al. 2012

Berkmann et al. 2014

Bohinski et al. 2001

Chen et al. 2012

Dort et al. 2001

Fomekong et al. 2014

Garcia et al. 2017

Gohla et al. 2019

Hlavac et al. 2019

Hlavica et al. 2013

Jimenez et al. 2016

Kuge et al. 2013

Li et al. 2015

Martin et al. 1999

Netuka et al. 2011

Nimsky et al. 2004

Nimsky et al. 2006

Pal'a et al. 2017

Paterno et al. 2014

Qiu et al. 2012

Ramm-Pettersen et al. 2011

Schwartz et al. 2006

Serra et al. 2016

Staartjes et al. 2019

Steinmeier et al. 1998

Strange et al. 2019

Sylvester et al. 2015

Szerlip et al. 2011

Tanei et al. 2013

Wu et al. 2009

Zaidi et al. 2016

Zhang et al. 2017

Zhang et al. 2019
$\Delta$ GTR Total

$10 \quad 51$

$24 \quad 115$

$19 \quad 85$

$9 \quad 29$

513

315

1073

630

642

$10 \quad 111$

$22 \quad 104$

$6 \quad 18$

235

630

25

1149

$15 \quad 48$

$20 \quad 85$

1296

$26 \quad 49$

$4 \quad 49$

420

115

$15 \quad 51$

$27 \quad 95$

318

$\begin{array}{ll}9 & 231\end{array}$

$12 \quad 156$

1353

414

$14 \quad 55$

420

$\begin{array}{ll}19 & 137\end{array}$

$28 \quad 133$

2130

Random effects model

Heterogeneity: $I^{2}=78 \%, \tau^{2}=0.0143, p<0.01$
Proportion

95\%-Cl Weight

$0.20[0.10 ; 0.33] \quad 3.1 \%$

$0.21[0.14 ; 0.29] \quad 3.7 \%$

$0.22[0.14 ; 0.33] \quad 3.5 \%$

$0.31[0.15 ; 0.51] \quad 2.6 \%$

$0.38[0.14 ; 0.68] \quad 1.8 \%$

$0.20[0.04 ; 0.48] \quad 2.0 \%$

$0.14[0.07 ; 0.24] \quad 3.4 \%$

$0.20[0.08 ; 0.39] \quad 2.7 \%$

$0.14[0.05 ; 0.29] \quad 3.0 \%$

$0.09[0.04 ; 0.16] \quad 3.6 \%$

$0.21[0.14 ; 0.30] \quad 3.6 \%$

$0.33[0.13 ; 0.59] \quad 2.2 \%$

$0.06[0.01 ; 0.19] \quad 2.8 \%$

$0.20[0.08 ; 0.39] \quad 2.7 \%$

$0.40[0.05 ; 0.85] \quad 1.0 \%$

$0.22[0.12 ; 0.37] \quad 3.1 \%$

$0.31[0.19 ; 0.46] \quad 3.1 \%$

$0.24[0.15 ; 0.34] \quad 3.5 \%$

$0.12[0.07 ; 0.21] \quad 3.6 \%$

$0.53[0.38 ; 0.67] \quad 3.1 \%$

$0.08[0.02 ; 0.20] \quad 3.1 \%$

$0.20[0.06 ; 0.44] \quad 2.3 \%$

$0.07[0.00 ; 0.32] \quad 2.0 \%$

$0.29[0.17 ; 0.44] \quad 3.1 \%$

$0.28 \quad[0.20 ; 0.39] \quad 3.6 \%$

$0.17[0.04 ; 0.41] \quad 2.2 \%$

$0.04[0.02 ; 0.07] \quad 3.9 \%$

$0.08[0.04 ; 0.13] \quad 3.8 \%$

$0.25[0.14 ; 0.38] \quad 3.2 \%$

0.29 [0.08; 0.58$] \quad 1.9 \%$

$0.25[0.15 ; 0.39] \quad 3.2 \%$

$0.20[0.06 ; 0.44] \quad 2.3 \%$

$0.14[0.09 ; 0.21] \quad 3.7 \%$

$0.21[0.14 ; 0.29] \quad 3.7 \%$

$0.19[0.15 ; 0.23] 100.0 \%$

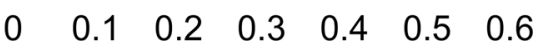 GTR Conversion}

Fig. 1 Forest plot representing the results of the statistical meta-analysis of the change in gross total resection ( $\Delta$ GTR) in percent from intraoperative to postoperative imaging 
Table 3 Patient-weighted means of the two outcomes not amenable to formal metaanalysis. For residual volume, a subgroup analysis of endo- and microscopic cases was feasible

\begin{tabular}{lll}
\hline Parameter & $\mathrm{N}$ & $\begin{array}{l}\text { Case- } \\
\text { weighted } \\
\text { mean }\end{array}$ \\
\hline
\end{tabular}

$\Delta \mathrm{EOR}(\%)$

Overall $\quad 191 \quad 9.07$

$\Delta \mathrm{RV}\left(\mathrm{cm}^{3}\right)$

Overall $\quad 387 \quad 0.784$

Endoscopic $73 \quad 0.503$

Microscopic $134 \quad 1.183$

$E O R$ extent of resection, $R V$ residual volume benefit is clearer such as those with suprasellar extension has been suggested as a viable strategy to further reduce costs [20]. Predictive tools such as the Zurich pituitary score, which has demonstrated its ability to predict in which patients ioMRI may be most useful, could be used for cost-benefit assessment [9, 11, 12]. When applying the Zurich pituitary score, it has been found that ioMRI is most useful in Grade I and II patients-small tumors-where GTR can almost always be achieved in a safe fashion when ioMRI is applied, compared to Grade IV adenomas which are seldom amenable to GTR anyway-In these patients, ioMRI can serve to increase EOR.

Past literature correctly points out at the main concern in evaluating ioMRI results, namely that knowledge of ioMRI availability may result in a more conservative first resection, falsely increases the conversion rate enabled by ioMRI [13, $16,24,48,55]$. Randomized studies comparing ioMRI to noioMRI are not available and none are ongoing. Some authors report that intra-operative imaging was pursued only when the neurosurgeon believed GTR had been achieved or when additional potentially unnecessary exploration was feared due to the risk of complications or morbidity [52]. Important concerns remain related to selection bias, lack of blinding in the evaluation of the resection, and a lack of randomized studies. Irrespective of this bias, reports about the early intraoperative identification of complications and proven advantages such as increasing maximally safe resection add to the evidence supporting the use of ioMRI [20]. Future studies evaluating the use of ioMRI should ideally assess not only GTR but also
EOR an RV quantitatively to better evaluate its contribution and to allow formal meta-analysis [13].

\section{Limitations}

The main limitation is that there are no data stemming from randomized studies. This only allows us to describe the realworld improvements in GTR, EOR, and RV observed, without considering the implicit biases described above. Due to the substantial heterogeneity observed, our results have to be interpreted with some caution and suggest a large variability in the use and consequences of ioMRI in different centers. Intrinsic biases of included publications cannot be ruled out. EOR and RV were evaluated using very limited data from only few studies. Because of a lack of granularity in the data identified in our systematic review, we were unable to perform stratification for functioning versus non-functioning adenoma. Additionally, we did not include endocrinological remission as an outcome of interest. Tumor size stratification was not possible, limiting our insights on the benefit of ioMRI for small versus large adenomas. Other outcomes such as safety and cost-effectiveness were not investigated.

\section{Conclusion}

Our meta-analysis demonstrates that around one fifth of patients undergoing pituitary adenoma resection convert from non-GTR to GTR after the use of ioMRI, in accordance with previous findings. EOR and RV can also be improved to a certain extent using ioMRI. When considering GTR, the benefit of ioMRI does not change for endoscopic versus microscopic transsphenoidal surgery, nor does field strength seem to influence results. Statistical heterogeneity was high, indicating that the improvement in surgical results due to ioMRI varies considerably by center. While it is likely that ioMRI truly increases GTR and EOR and leads to lower RV, only randomized studies can take this question to a higher level of evidence by avoiding the implicit biases introduced through the mere use of ioMRI. Regardless, future studies on ioMRI should provide quantitative assessment of surgical results, including volumetric assessment of EOR and RV. 


\section{Endoscopic}

\section{Study}

Garcia et al. 2017

Hlavac et al. 2019

Jimenez et al. 2016

Kuge et al. 2013

Pal'a et al. 2017

Paterno et al. 2014

Schwartz et al. 2006

Serra et al. 2016

Staartjes et al. 2019

Strange et al. 2019

Tanei et al. 2013

Zaidi et al. 2016

Zhang et al. 2017

Zhang et al. 2019

Random effects model

Heterogeneity: $I^{2}=90 \%, \tau^{2}=0.0333, p<0.01$
$\Delta$ GTR Total

$\begin{array}{rr}6 & 30 \\ 3 & 111 \\ 6 & 18 \\ 2 & 35 \\ 3 & 96 \\ 26 & 49 \\ 1 & 15 \\ 15 & 51 \\ 27 & 95 \\ 9 & 231 \\ 4 & 14 \\ 4 & 20 \\ 19 & 137 \\ 28 & 133\end{array}$

1035

0

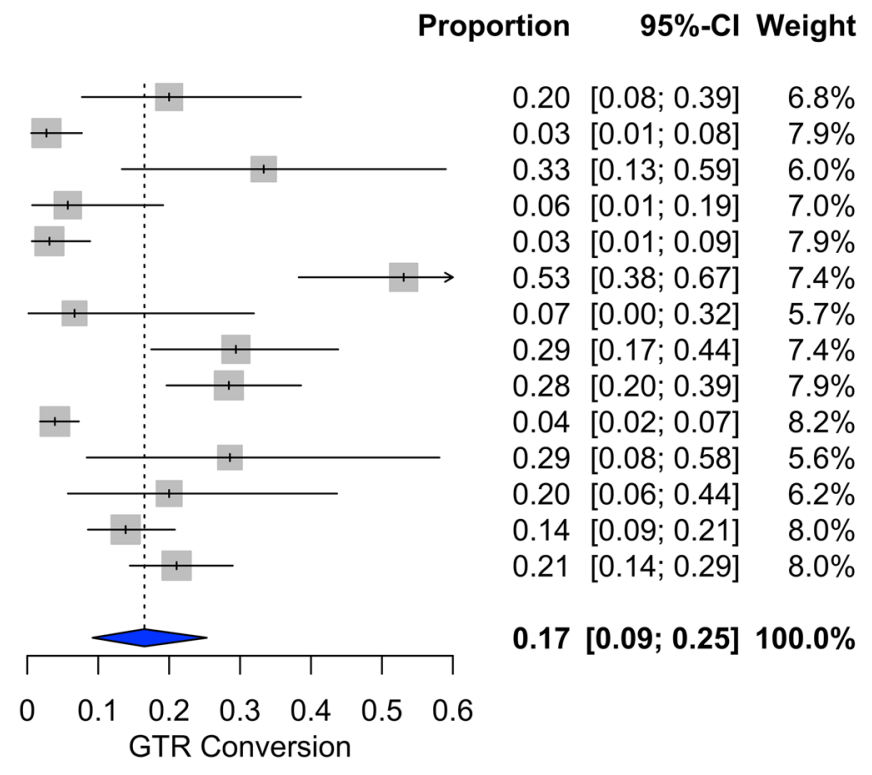

\section{Microscopic}

\section{Study}

Ahn et al. 2008

Berkmann et al. 2014

Berkmann et al. 2012

Bohinski et al. 2001

Chen et al. 2012

Dort et al. 2001

Fomekong et al. 2014

Gohla et al. 2019

Hlavac et al. 2019

Hlavica et al. 2013

Li et al. 2015

Martin et al. 1999

Nimsky et al. 2006

Nimsky et al. 2004

Pal'a et al. 2017

Ramm-Pettersen et al. 2011

Steinmeier et al. 1998

Szerlip et al. 2011

Wu et al. 2009

Random effects model

Heterogeneity: $I^{2}=56 \%, \tau^{2}=0.0058, p<0.01$
$\Delta$ GTR Total

$\begin{array}{lr}10 & 51 \\ 19 & 85 \\ 24 & 115\end{array}$

$\begin{array}{rr}24 & 115 \\ 9 & 29\end{array}$

$5 \quad 13$

315

1073

$\begin{array}{ll}7 & 111\end{array}$

$22 \quad 104$

630

25

$20 \quad 85$

$15 \quad 48$

996

420

318

1353

1455

1048
642

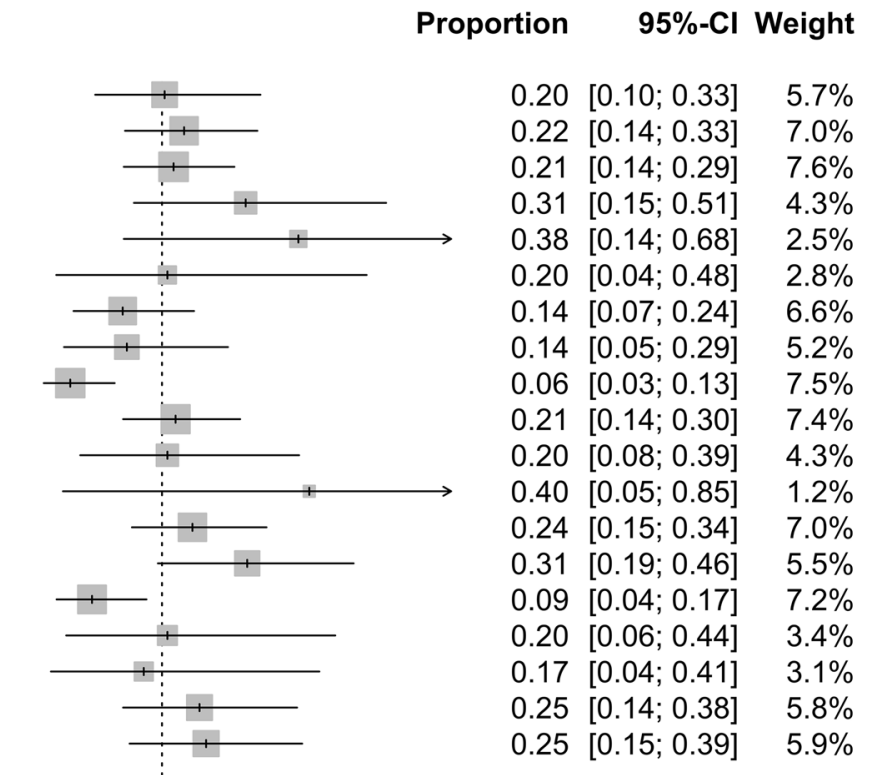

$0.19[0.15 ; 0.23] 100.0 \%$

Fig. 2 Stratified analysis of endoscopic versus microscopic surgery. Forest plots represent the results of the statistical meta-analysis of the change in gross total resection ( $\triangle \mathrm{GTR}$ ) in percent from intraoperative to postoperative imaging 
Low Field iMRI

Study

Ahn et al. 2008

Berkmann et al. 2012

Bohinski et al. 2001

Garcia et al. 2017

Hlavica et al. 2013

Jimenez et al. 2016

Martin et al. 1999

Ramm-Pettersen et al. 2011

Schwartz et al. 2006

Steinmeier et al. 1998

Strange et al. 2019

Wu et al. 2009

Random effects model

Heterogeneity: $I^{2}=81 \%, \tau^{2}=0.0206, p<0.01$
$\Delta$ GTR Total

$\begin{array}{rr}10 & 51 \\ 24 & 115 \\ 9 & 29 \\ 6 & 30 \\ 22 & 104 \\ 6 & 18 \\ 2 & 5 \\ 4 & 20 \\ 1 & 15 \\ 3 & 18 \\ 9 & 231\end{array}$

$14 \quad 55$

691

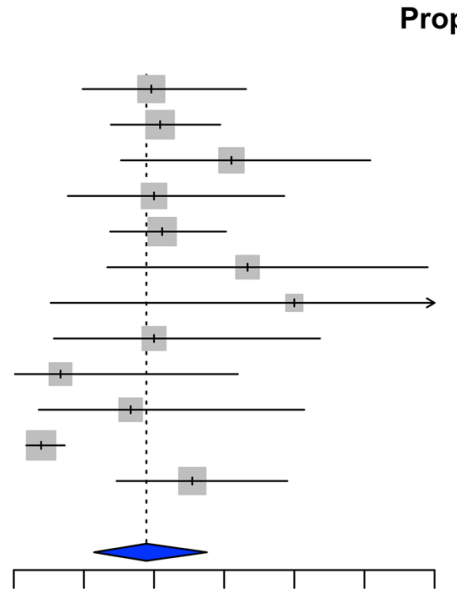

Proportion $\quad 95 \%-\mathrm{Cl}$ Weight

$0.20[0.10 ; 0.33] \quad 9.5 \%$

$0.21[0.14 ; 0.29] \quad 10.6 \%$

$0.31[0.15 ; 0.51] \quad 8.3 \%$

$0.20[0.08 ; 0.39] \quad 8.4 \%$

$0.21[0.14 ; 0.30] \quad 10.5 \%$

$0.33[0.13 ; 0.59] \quad 7.1 \%$

$0.40[0.05 ; 0.85] \quad 3.7 \%$

$0.20[0.06 ; 0.44] \quad 7.4 \%$

$0.07[0.00 ; 0.32] \quad 6.6 \%$

$0.17[0.04 ; 0.41] \quad 7.1 \%$

$0.04[0.02 ; 0.07] \quad 11.2 \%$

$0.25[0.15 ; 0.39] \quad 9.6 \%$

$0.19[0.11 ; 0.28] 100.0 \%$

\section{Study}

Berkmann et al. 2014

Chen et al. 2012

Dort et al. 2001

Fomekong et al. 2014

Gohla et al. 2019

Hlavac et al. 2019

Kuge et al. 2013

Li et al. 2015

Netuka et al. 2011

Nimsky et al. 2004

Nimsky et al. 2006

Pal'a et al. 2017

Paterno et al. 2014

Qiu et al. 2012

Serra et al. 2016

Staartjes et al. 2019

Sylvester et al. 2015

Szerlip et al. 2011

Tanei et al. 2013

Zaidi et al. 2016

Zhang et al. 2017

Zhang et al. 2019

Random effects model

Heterogeneity: $I^{2}=76 \%, \tau^{2}=0.0123, p<0.01$

$\Delta$ GTR Total

\section{$19 \quad 85$}

513

315

1073

642

$10 \quad 111$

235

630

1149

1548

$20 \quad 85$

$12 \quad 96$

$26 \quad 49$

$15 \quad 51$

$27 \quad 95$

$12 \quad 156$

1353

414

420

$\begin{array}{ll}19 & 137\end{array}$

$28 \quad 133$

1439

\section{High Field iMRI}

449

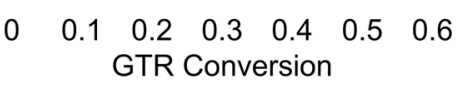

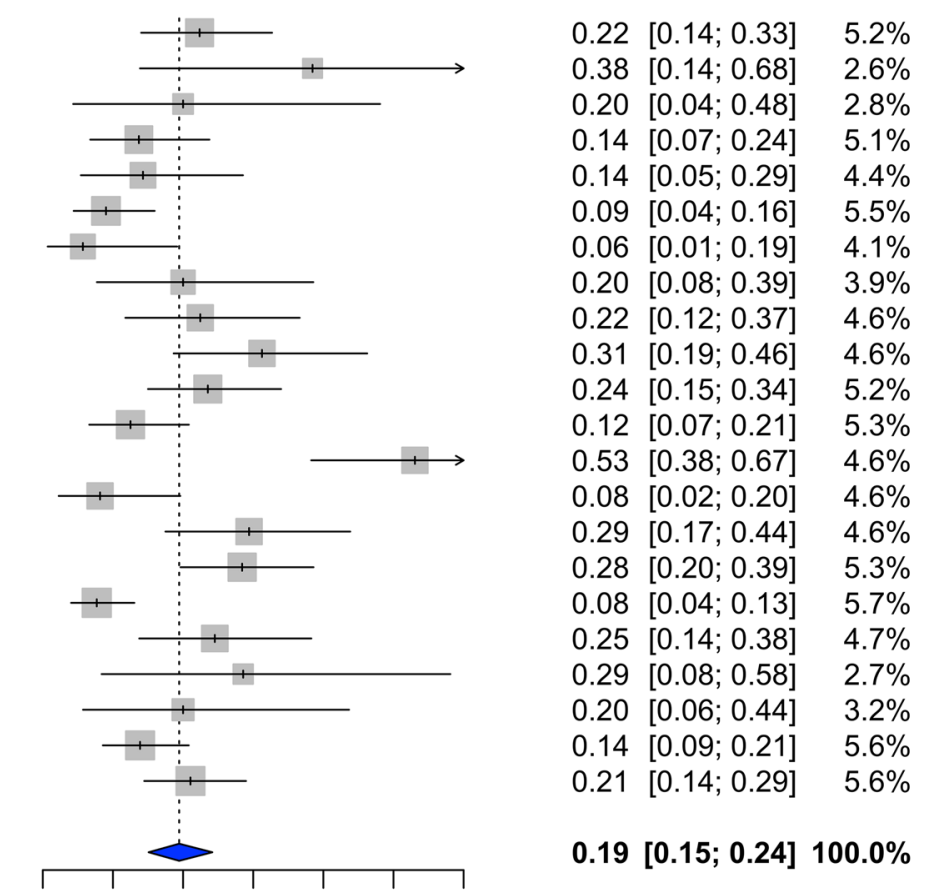

Fig. 3 Stratified analysis of low-field versus high-field transsphenoidal surgery. Forest plots represent the results of the statistical meta-analysis of the change in gross total resection $(\triangle \mathrm{GTR})$ in percent from intraoperative to postoperative imaging 


\section{Ultra High Field iMRI}

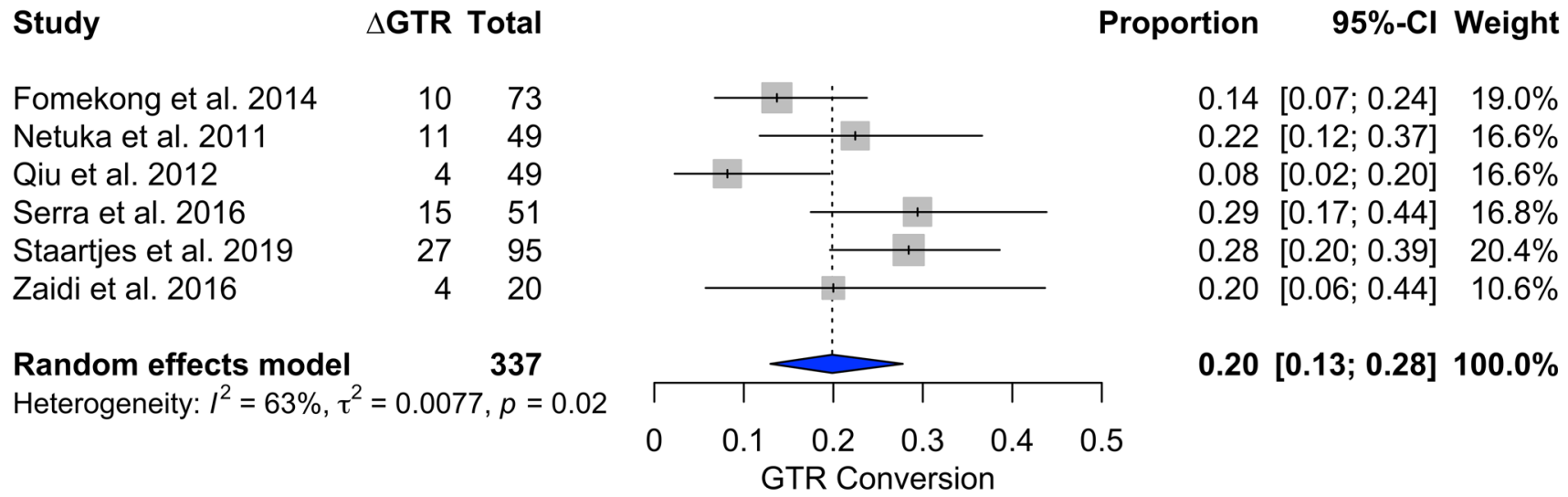

Fig. 4 Forest plot of studies including ultra high-field intraoperative MRI, representing the results of the statistical meta-analysis of the change in gross total resection $(\Delta \mathrm{GTR})$ in percent from intraoperative to postoperative imaging

\section{Declarations}

\section{Conflict of interest}

The authors declare that the article and its content were composed in the absence of any commercial or financial relationships that could be construed as a potential conflict of interest.

Supplementary Information The online version contains supplementary material available at https://doi.org/10.1007/s11102-021-01147-2.

Funding Open Access funding provided by Universität Zürich. This research did not receive any specific grant from funding agencies in the public, commercial, or not-for-profit sectors.

Open Access This article is licensed under a Creative Commons Attribution 4.0 International License, which permits use, sharing, adaptation, distribution and reproduction in any medium or format, as long as you give appropriate credit to the original author(s) and the source, provide a link to the Creative Commons licence, and indicate if changes were made. The images or other third party material in this article are included in the article's Creative Commons licence, unless indicated otherwise in a credit line to the material. If material is not included in the article's Creative Commons licence and your intended use is not permitted by statutory regulation or exceeds the permitted use, you will need to obtain permission directly from the copyright holder. To view a copy of this licence, visit http://creativecommons.org/licenses/by/4.0/.

\section{References}

1. Araujo-Castro M, Berrocal VR, Pascual-Corrales E (2020) Pituitary tumors: epidemiology and clinical presentation spectrum. Hormones 19:145-155. https://doi.org/10.1007/ s42000-019-00168-8

2. Almutairi RD, Muskens IS, Cote DJ et al (2018) Gross total resection of pituitary adenomas after endoscopic vs. microscopic transsphenoidal surgery: a meta-analysis. Acta Neurochir 160:10051021. https://doi.org/10.1007/s00701-017-3438-z

3. Ammirati M, Wei L, Ciric I (2013) Short-term outcome of endoscopic versus microscopic pituitary adenoma surgery: a systematic review and meta-analysis. J Neurol Neurosurg Psychiatry 84:843-849. https://doi.org/10.1136/jnnp-2012-303194

4. Goudakos JK, Markou KD, Georgalas C (2011) Endoscopic versus microscopic trans-sphenoidal pituitary surgery: a systematic review and meta-analysis. Clin Otolaryngol 36:212-220. https:// doi.org/10.1111/j.1749-4486.2011.02331.x

5. Molitch ME (2013) Management of medically refractory prolactinoma. J Neurooncol 117:421-428. https://doi.org/10.1007/ s11060-013-1270-8

6. Dallapiazza RF, Grober Y, Starke RM et al (2015) Long-term results of endonasal endoscopic transsphenoidal resection of non functioning pituitary macro adenomas. Neurosurgery 76(1):4252. https://doi.org/10.1227/NEU.0000000000000563

7. Micko ASG, Wöhrer A, Wolfsberger S, Knosp E (2015) Invasion of the cavernous sinus space in pituitary adenomas: endoscopic verification and its correlation with an MRI-based classification. J Neurosurg 122:803-811. https://doi.org/10.3171/2014.12.JNS14 1083

8. Meij BP, Lopes M-BS, Ellegala DB et al (2002) The long-term significance of microscopic dural invasion in 354 patients with pituitary adenomas treated with transsphenoidal surgery. J Neurosurg 96:195-208. https://doi.org/10.3171/jns.2002.96.2.0195

9. Serra C, Staartjes VE, Maldaner N et al (2018) Predicting extent of resection in transsphenoidal surgery for pituitary adenoma. Acta Neurochir 160:2255-2262. https://doi.org/10.1007/ s00701-018-3690-x

10. Hofstetter CP, Nanaszko MJ, Mubita LL et al (2012) Volumetric classification of pituitary macroadenomas predicts outcome and morbidity following endoscopic endonasal transsphenoidal surgery. Pituitary 15:450-463. https://doi.org/10.1007/ s11102-011-0350-z

11. Staartjes VE, Serra C, Maldaner N et al (2019) The Zurich pituitary score predicts utility of intraoperative high-field magnetic 
resonance imaging in transsphenoidal pituitary adenoma surgery. Acta Neurochir 161:2107-2115. https://doi.org/10.1007/ s00701-019-04018-9

12. Staartjes VE, Serra C, Zoli M et al (2020) Multicenter external validation of the Zurich pituitary score. Acta Neurochir 162:12871295. https://doi.org/10.1007/s00701-020-04286-w

13. Serra C, Burkhardt J-K, Esposito G et al (2016) Pituitary surgery and volumetric assessment of extent of resection: a paradigm shift in the use of intraoperative magnetic resonance imaging. Neurosurg Focus 40:E17. https://doi.org/10.3171/2015.12.FOCUS 15564

14. Jones PS, Swearingen B (2019) Intraoperative MRI for pituitary adenomas. Neurosurg Clin North Am 30:413-420. https://doi.org/ 10.1016/j.nec.2019.05.003

15. Soneru CP, Riley CA, Hoffman K et al (2019) Intra-operative MRI vs endoscopy in achieving gross total resection of pituitary adenomas: a systematic review. Acta Neurochir 161:1683-1698. https://doi.org/10.1007/s00701-019-03955-9

16. Nimsky C, Keller BV, Ganslandt O, Fahlbusch R (2006) Intraoperative high-field magnetic resonance imaging in transsphenoidal surgery of hormonally inactivepituitary macroadenomas. Neurosurgery 59:105-114. https://doi.org/10.1227/01.NEU.00002 19198.38423.1E

17. Pal'a A, Knoll A, Brand C et al (2017) The value of intraoperative magnetic resonance imaging in endoscopic and microsurgical transsphenoidal pituitary adenoma resection. World Neurosurg 102:144-150. https://doi.org/10.1016/j.wneu.2017.02.132

18. Hlavica M, Bellut D, Lemm D et al (2013) Impact of ultra-lowfield intraoperative magnetic resonance imaging on extent of resection and frequency of tumor recurrence in 104 surgically treated nonfunctioning pituitary adenomas. World Neurosurg 79:99-109. https://doi.org/10.1016/j.wneu.2012.05.032

19. Zaidi HA, De Los RK, Barkhoudarian G et al (2016) The utility of high-resolution intraoperative MRI in endoscopic transsphenoidal surgery for pituitary macroadenomas: early experience in the advanced multimodality image guided operating suite. Neurosurg Focus 40:E18. https://doi.org/10.3171/2016.1.FOCUS15515

20. Bohinski RJ, Warnick RE, Gaskill-Shipley MF et al (2001) Intraoperative magnetic resonance imaging to determine the extent of resection of pituitary macroadenomas during transsphenoidal microsurgery. Neurosurgery 49(5):1133-1144. https://doi.org/10. 1097/00006123-200111000-00023

21. do Amaral LC, Reis BL, Ribeiro-Oliveira A et al (2020) Comparative study of complications after primary and revision transsphenoidal endoscopic surgeries. Neurosurg Rev. https://doi.org/ 10.1007/s10143-020-01360-w

22. García S, Reyes L, Roldán P et al (2017) Does low-field intraoperative magnetic resonance improve the results of endoscopic pituitary surgery? Experience of the implementation of a new device in a referral center. World Neurosurg 102:102-110. https:// doi.org/10.1016/j.wneu.2017.02.094

23. Nimsky C, Ganslandt O, Von Keller B et al (2004) Intraoperative high-field-strength MR imaging: implementation and experience in 200 patients. Radiology 233:67-78. https://doi.org/10.1148/ radiol.2331031352

24. Wu JS, Shou XF, Yao CJ et al (2009) Transsphenoidal pituitary macroadenomas resection guided by PoleStar N20 low-field intraoperative magnetic resonance imaging: comparison with early postoperative high-field magnetic resonance imaging. Neurosurgery 65(1):63-71. https://doi.org/10.1227/01.NEU.0000348549. 26832.51

25. Moher D, Liberati A, Tetzlaff J et al (2009) Preferred reporting items for systematic reviews and meta-analyses: the PRISMA statement. BMJ 339:b2535-b2535. https://doi.org/10.1136/bmj. b2535
26. Chittiboina $P$ (2017) iMRI during transsphenoidal surgery (TSS). Neurosurg Clin North Am 28:499-512. https://doi.org/10.1016/j. nec.2017.05.005

27. Deeks J, Dinnes J, D'Amico R et al (2003) Evaluating non-randomised intervention studies. Health Technol Assess. https://doi. org/10.3310/hta7270

28. Borenstein M, Hedges LV, Higgins JPT, Rothstein HR (2010) A basic introduction to fixed-effect and random-effects models for meta-analysis. Res Synth Methods 1:97-111. https://doi.org/10. $1002 /$ jrsm. 12

29. DerSimonian R, Laird N (1986) Meta-analysis in clinical trials. Control Clin Trials 7:177-188. https://doi.org/10.1016/01972456(86)90046-2

30. Schwarzer G (2020) Meta: general package for meta-analysis. https://cran.r-project.org/web/packages/meta/index.html. Accessed 2 July 2020

31. Ahn JY, Jung JY, Kim J et al (2008) How to overcome the limitations to determine the resection margin of pituitary tumours with low-field intra-operative MRI during trans-sphenoidal surgery: usefulness of Gadolinium-soaked cotton pledgets. Acta Neurochir 150:763-771. https://doi.org/10.1007/s00701-008-1505-1

32. Berkmann S, Fandino J, Müller B et al (2012) Pituitary surgery: experience from a large network in Central Switzerland. Swiss Med Wkly 142:w13680. https://doi.org/10.4414/smw.2012.13680

33. Jiménez P, Brell M, Sarriá-Echegaray P et al (2016) "Intrasellar balloon technique" in intraoperative MRI guided transsphenoidal endoscopic surgery for sellar region tumors. Usefulness on image interpretation and extent of resection evaluation. Tech Note Acta Neurochir 158:445-449. https://doi.org/10.1007/ s00701-015-2697-9

34. Martin CH, Schwartz R, Jolesz F, Black PM (1999) Transsphenoidal resection of pituitary adenomas in an intraoperative MRI unit. Pituitary 2:155-162. https://doi.org/10.1023/a:1009943700 810

35. Ramm-Pettersen J, Berg-Johnsen J, Hol PK et al (2011) Intraoperative MRI facilitates tumour resection during trans-sphenoidal surgery for pituitary adenomas. Acta Neurochir 153:13671373. https://doi.org/10.1007/s00701-011-1004-7

36. Schwartz TH, Stieg PE, Anand VK (2006) Endoscopic transsphenoidal pituitary surgery with intraoperative magnetic resonance imaging. Oper Neurosurg. https://doi.org/10.1227/01.NEU.00001 93927.49862.B6

37. Strange F, Remonda L, Schütz P et al (2020) 10 years' experience of using low-field intraoperative MRI in transsphenoidal surgery for pituitary adenoma: results of the Swiss pituitary registry (SwissPit). World Neurosurg 136:e284-e293. https://doi.org/10. 1016/j.wneu.2019.12.146

38. Steinmeier R, Fahlbusch R, Ganslandt O et al (1998) Intraoperative magnetic resonance imaging with the magnetom open scanner: concepts, neurosurgical indications, and procedures: a preliminary report. Neurosurgery 43(4):739-747. https://doi.org/ 10.1097/00006123-199810000-00005

39. Berkmann S, Schlaffer S, Nimsky C et al (2014) Intraoperative high-field MRI for transsphenoidal reoperations of nonfunctioning pituitary adenoma. J Neurosurg 121:1166-1175. https://doi.org/ 10.3171/2014.6.JNS131994

40. Chen X, Xu B, Meng X et al (2011) Dual-room 1.5-T intraoperative magnetic resonance imaging suite with a movable magnet: implementation and preliminary experience. Neurosurg Rev 35:95-110. https://doi.org/10.1007/s10143-011-0336-3

41. Dort JC, Sutherland GR (2001) Intraoperative magnetic resonance imaging for skull base surgery. Laryngoscope 111:1570-1575. https://doi.org/10.1097/00005537-200109000-00014

42. Fomekong E, Duprez T, Docquier MA et al (2014) Intraoperative 3T MRI for pituitary macroadenoma resection: Initial experience 
in 73 consecutive patients. Clin Neurol Neurosurg 126:143-149. https://doi.org/10.1016/j.clineuro.2014.09.001

43. Gohla G, Bender B, Tatagiba M et al (2019) Identification of tumor residuals in pituitary adenoma surgery with intraoperative MRI: do we need gadolinium? Neurosurg Rev 43:1623-1629. https://doi.org/10.1007/s10143-019-01202-4

44. Hlaváč M, Knoll A, Etzrodt-Walter G et al (2019) Intraoperative MRI in transsphenoidal resection of invasive pituitary macroadenomas. Neurosurg Rev 42:737-743. https://doi.org/10.1007/ s10143-019-01102-7

45. Kikuchi Z, Sato S, Sakurada K et al (2013) Practical use of a simple technique, insertion of wet cotton pledgets into the tumor resection cavity in transsphenoidal surgery of pituitary tumors, for a better comparison between pre- and intraoperative high-field magnetic resonance images. J Neurol Surg Part A 74:366-372. https://doi.org/10.1055/s-0033-1349342

46. Li J, Cong Z, Ji X et al (2015) Application of intraoperative magnetic resonance imaging in large invasive pituitary adenoma surgery. Asian J Surg 38:168-173. https://doi.org/10.1016/j.asjsur. 2015.03.001

47. Netuka D, Masopust V, Belšán T et al (2011) One year experience with 3.0 T intraoperative MRI in pituitary surgery. In: Pamir MN, Seifert V, Kiris T (eds) Intraoperative imaging. Springer Vienna, Vienna, pp 109-157

48. Paterno V, Fahlbusch R (2014) High-Field iMRI in transsphenoidal pituitary adenoma surgery with special respect to typical localization of residual tumor. Acta Neurochir 156(3):463-474. https://doi.org/10.1007/s00701-013-1978-4

49. Sylvester PT, Evans JA, Zipfel GJ et al (2015) Combined highfield intraoperative magnetic resonance imaging and endoscopy increase extent of resection and progression-free survival for pituitary adenomas. Pituitary 18:72-85. https://doi.org/10.1007/ s11102-014-0560-2

50. Szerlip NJ, Zhang YC, Placantonakis DG et al (2011) Transsphenoidal resection of sellar tumors using high-field intraoperative magnetic resonance imaging. Skull Base 21:223-232. https://doi. org/10.1055/s-0031-1277262

51. Tanei T, Nagatani T, Nakahara $\mathrm{N}$ et al (2013) Use of high-field intraoperative magnetic resonance imaging during endoscopic transsphenoidal surgery for functioning pituitary microadenomas and small adenomas located in the intrasellar region. Neurol Med Chir 53:501-510. https://doi.org/10.2176/nmc.53.501

52. Zhang Z, Yang K, Xia Y et al (2019) High-field intraoperative magnetic resonance imaging increases extent of resection and progression-free survival for nonfunctioning pituitary adenomas. World Neurosurg 127:e925-e931. https://doi.org/10.1016/j.wneu. 2019.04.001

53. Zhang H, Wang F, Zhou T et al (2017) Analysis of 137 patients who underwent endoscopic transsphenoidal pituitary adenoma resection under high-field intraoperative magnetic resonance imaging navigation. World Neurosurg 104:802-815. https://doi. org/10.1016/j.wneu.2017.04.056

54. Qiu T, Yao C, Wu J et al (2012) Clinical experience of 3 T intraoperative magnetic resonance imaging integrated neurosurgical suite in Shanghai Huashan hospital. Chin Med J 125:4328-4333

55. Berkmann S, Schlaffer S, Nimsky C et al (2014) Follow-up and long-term outcome of nonfunctioning pituitary adenoma operated by transsphenoidal surgery with intraoperative high-field magnetic resonance imaging. Acta Neurochir 156(12):2233-2243. https:// doi.org/10.1007/s00701-014-2210-x

56. Powell M (2011) The value of intra-operative MRI in trans-sphenoidal pituitary surgery. Acta Neurochir 153:1375-1376. https:// doi.org/10.1007/s00701-011-1005-6

57. Buchfelder M, Schlaffer SM (2012) Intraoperative magnetic resonance imaging during surgery for pituitary adenomas: pros and cons. Endocrine 42:483-495. https://doi.org/10.1007/ s12020-012-9752-6

58. Fahlbusch R, Keller BV, Ganslandt O et al (2005) Transsphenoidal surgery in acromegaly investigated by intraoperative high-field magnetic resonance imaging. Eur J Endocrinol 153:239-248. https://doi.org/10.1530/eje.1.01970

Publisher's Note Springer Nature remains neutral with regard to jurisdictional claims in published maps and institutional affiliations. 